\title{
Alerginio rinito gydymo efektyvumas priklauso nuo tinkamai pasirinkto
}

\section{vaisto}

\author{
Ieva Bajoriūnienė, Virginija Kalinauskaitė \\ LSMU MA Pulmonologijos ir imunologijos klinika
}

Reikšminiai žodžiai: vidutinio sunkumo, sunkus alerginis rinitas, azelastinas, flutikazonas.

Santrauka. Pastaruoju metu augant alerginėmis ligomis sergančių asmenų skaičiui, didejja ir alerginio rinito (AR) nustatymo dažnumas. Europoje nuo AR kenčia 25 proc. [1], JAV - 30 proc. populiacijos [2]. Nors AR nera pavojingas gyvybei, tačiau neabejojama jo socioekonomine našta. Išlaidos, tenkančios AR gydymui, atsiliepia tiek ligoniui, tiek valstybei, 0 varginantys simptomai varžo paciento kasdienę veiklą, darbo galimybes, blogina gyvenimo kokybę. Vien tiesioginès medicinos išlaidos, tenkančios vieno Europos gyventojo, sergančio AR, gydymui per metus yra apie 4260 eurų, JAV - 3,4 mlrd. dolerių visiems AR sergantiems asmenims. Todèl pagrindinis ligonio ir ji prižiūrinčio gydytojo tikslas - kaip įmanoma greičiau sušvelninti AR simptomus arba jų visiškai išvengti, skiriant tinkamą, naujausiais moksliniais tyrimais pagrįstą gydymą. Geru AR gydomuoju poveikiu (efektyviai mažinančiu nosies ir akių simptomus sergant vidutinio sunkumo ar sunkiu AR), vaisto saugumu klinikiniuose tyrimuose pasižymėjo Dymista ${ }^{\circledast}$ (azelastine hydrochloride/fluticasone propionate).

\section{ALERGINIS RINITAS - NUO ETIOLOGIJOS IKI GYDYMO}

Alerginis rinitas apibrèžiamas kaip alergenų sukeltas ir IgE nulemtas dažniausiai lètinis nosies gleivinès uždegimas su būdingais požymiais (vienu ar daugiau): nosies užburkimu, vandeningo sekreto varvejjimu iš nosies, čiauduliu, nosies niežuliu [3, 4]. Galimas ir sekreto tekejjimo pojūtis gerklèje, galvos, ausų skausmas, gerklès perštėjimas, sutrikęs miegas. Pagrindiniai AR etiologiniai veiksniai yra šie: namų dulkių erkès (Dermatophagoides pteronyssinus, Dermatophagoides farinae), naminių gyvūnų (kačių, šunų, triušių, jūrų kiaulyčių ir kt.) epidermis, vabzdžiai (tarakonai), pelèsiniai grybeliai (Alternaria arternata, Penicillium, Aspergillus), medžių (beržų, lazdynų, alksnių ir kt.), žolių (motiejukų, miglių, eraičinų ir kt.) ir piktžolių žiedadulkès, sezoninių mikroskopinių grybų sporos [5], kiti alergenai. AR pagal skirtingas klasifikacijas skiriamas $\mathfrak{i}$ epizodini ir nuolatini nepriklausantị. Remiantis ARIA (angl. Allergic Rhinitis and its Impact on Asthma, liet. Alerginis rinitas ir jo itaka astmai) gairemis, pastaruoju metu naudojama AR skirstymo ị epizodini ir nuolatinị klasifikacija. Aprašant anksčiau atliktus klinikinius tyrimus, naudojama ir sezoninio bei nuo sezono nepriklausančio AR sąvokos. Epizodinio. Epizodinio AR simptomai trunka ne daugiau kaip 4 dienas per savaitę ir ne ilgiau kaip 4 savaites. Būdingas sezoniškumas ir cikliškumas. Kliniškai epizodinis AR dažniausiai pasireiškia nosies niežuliu, čiauduliu, rinorèja, kartu būna alerginio konjunktyvito požymių. Nuolatinio AR simptomai vargina daugiau nei 4 dienas per savaitę ir trunka ilgiau nei 4 savaites. Nuolatinis AR tęsiasi beveik ištisus metus, būdingas nosies užgulimas, neretai kartu diagnozuojamas ir rinosinusitas, astma. Pagal ligos eigą AR gali būti lengvas, vidutinio sunkumo ir sunkus. Esant lengvam rinitui, juntami simptomai minimalūs, nevargina paciento, nereikia riboti kasdienès veiklos. Kai rinitas vidutinio sunkumo, sunkus, juntami simptomai pradeda varginti pacientą: sutrinka miegas, ribojama kasdienè veikla, susilpnejja dèmesio koncentracija [5]. Pastebèta, kad ilgainiui keičiasi AR klinikinis vaizdas [6-8]: sunkejja rinito eiga - nuo nesunkaus iki vidutinio sunkumo ir sunkaus [9], dažnesnès mišrios formos [7], daugiau pacientų įsijautrinę keliems alergenams (polisensibilizacija), atsiranda gydymui atsparių fenotipų (maždaug 30 proc. AR sergančių pacientų) [8].

Itarus AR, svarbu tiksliai surinkti anamnezę (ypač dèl galimo įsijautrinimo alergenams, kitų alerginių ligų). Apžiūrint pacientą, dažnai pastebima skersinè nosies raukšlè, ratilai paakiuose, „alergijos saliutas“ [3, 10]. Diagnozei patikslinti atliekami odos dūrio méginiai - dèl galimo ịsijautrinimo konkretiems alergenams, priekinės rinoskopijos metu apžiūrima nosies gleivinè, tam tikrais atvejais gali būti atliekama ir nosies endoskopija kitoms klinikinių simptomų priežastims paneigti. Papildomos informacijos teikia ir nosies sekreto citologinis tyrimas (ivertinamas eozinofilu kiekis nosies sekrete infekciniam rinitui paneigti). Gali būti tiriamas ir specifinis IgE, jei nèra galimybès atlikti odos dūrio mėginių.

Šiandieninèje farmacijos rinkoje yra daugybè vaistų, skirtu AR gydyti, todèl reikia laikytis tam tikrų gydy- 
mo principu $[2,5]$ : iš aplinkos šalinti alergenus ir nespecifinius dirgiklius (vengti kontakto su itariamais ar nustatytais alergenais); gydymą vaistais skirti pakopomis, priklausomai nuo ligos sunkumo, vaistus vartoti reguliariai, jei numatomas neišvengiamas kontaktas su alergenu tikslinga vaistą skirti anksti [3]. Dažniausiai klinikinejje praktikoje gydoma i nosi vartojamais vaistais, kurie yra AR gydymo pagrindas: antihistamininių vaistuc ir / ar gliukokortikoidu (GKK) purškalais [4, 11, 12]. Lengvos eigos epizodinis rinitas gydomas geriamaisiais arba $\mathfrak{i}$ nosị purškiamais antihistamininiais vaistais (sumažina niežèjimą, čiaudulị, sekreciją iš nosies, tačiau gana menkai veikia nosies užgulimą). Kartu gali būti skiriama dekongestantu (ne ilgiau kaip 5-7 dienas). Epizodinis vidutinio sunkumo ar sunkios eigos bei lengvos eigos nuolatinis AR dažniausiai gydomas pirmos eilès vaistais geriamaisiais II kartos $\mathrm{H} 1$ antihistamininiais preparatais ir/ar GKK nosies purškalais. Vaikams neretai skiriama kromonų, o sergantiems astma leukotrienu receptoriu antagonistuc. Svarbu reguliariai atlikti nosies tualetą, taip pat iki 5-7 dienu galima skirti dekongestantuc. Nuolatinis vidutinio sunkumo ar sunkios eigos AR gydomas GKK nosies purškalais. Jeigu po 2-4 savaičių būklè nepagerèja laikantis nurodyto gydymo režimo ir nèra infekcijos požymių, tikslinga padidinti i nosi purškiamų GKK dozę. Esant nosies niežuliui, čiauduliui pridedamas geriamasis II kartos $\mathrm{H} 1$ antihistamininis vaistas, o jei nosies gleivinè lieka užburkusi, rekomenduojama pridèti trumpą kursą dekongestanto ar geriamojo GKK. AR gydymui gali būti taikoma ir specifinè imunoterapija (SIT), atliekama su alergenų, kuriems pacientas yra ìsijautrinęs, ekstraktais (ugdomas specifinių alergenų toleravimas). SIT veiksmingumas siekia $80-90$ proc., tačiau toks gydymas trunka ilgai - 3-5 metus. SIT sustabdo įsijautrinimą naujiems alergenams, sumažina astmos riziką ir yra laikoma antrinès profilaktikos priemone [3, 13, 14]. Negydant AR, dažnai vystosi komplikacijos: rinosinusitas, vidurinès ausies eksudacinis uždegimas, nosies polipai, klausos sutrikimai, konjunktyvitai [3, 10].

Norint objektyvizuoti AR gydymo efektą, AR nosies ir akių simp- tomai vetinami balais ryte ir vakare pagal skalę nuo "0“ (simptomų nèra) iki „3“ (sunkūs), simptomų balus sudedant. Nosies simptomų balas (rTNSS) nustatomas pagal nosies užgulimą, nosies niežejjimą, išskyras iš nosies, čiauduli (didžiausias balas 24), akių simptomų balas (rTOSS) pagal akių niežèjimą, akių paraudimą, akių ašarojimą (didžiausias balas - 18).

\section{DYMISTA $^{\oplus}$}

Dymista $^{\odot}$ skiriama simptominiam vidutinio sunkumo ir sunkiam sezoniniam ir nuolatiniam AR gydyti, kai monoterapija nosies antihistamininiais vaistiniais preparatais ar GKK purškalais yra nepakankamai veiksminga [15] Dymista $^{\oplus}$ nosies purškale yra azelastino hidrochlorido ir flutikazono propionato, kuriuc veikimo mechanizmai skirtingi, todèl papildo vienas kito poveiki slopinant AR ir rinokonjunktyvito simptomus. Flutikazono propionatas - tai sintetinis GKK, o azelastinas priskiriamas prie stipriai ir ilgai veikiančiuc antihistamininiuc vaistinių preparatų, kuriam būdingos selektyvios H1 antagonistinès, putliąsias ląsteles stabilizuojančios ir uždegimą slopinančios savybès. In vivo ir in vitro tyrimu duomenys rodo, jog azelastinas slopina cheminių mediatorių, dalyvaujančiuc ankstyvosios ir vèlyvosios stadijos alerginèse reakcijose (leukotrienų, histamino, trombocitus aktyvinančio faktoriaus ir serotonino), sintezę ar atpalaidavimą.

\section{Naujausi klinikiniai tyrimai, irodantys Dymista $^{\circ}$ saugumą ir efektyvumą}

Atliktas ilgalaikis atsitiktinių imčių, paralelinių grupių vaisto saugumo tyrimas MP29-02, kuriame vertintas sudètinio i nosi purškiamo vaisto azelastino hidrochlorido ir flutikazono propionato (tyrimo metu žinomo kaip MP29-02, vėliau - kaip Dymista ${ }^{\circledast}$ ) specialiame purkštuve - efektyvumas ir saugumas gydant lètini alerginị ir nealerginị (vazomotorinį) rinitą [17]. Tyrimas truko vienerius metus, jame dalyvavo 612 asmenų, lètiniu rinitu sergančiuc ne trumpiau kaip vienerius metus. Tiriamieji atsitiktine tvarka buvo suskirstyti i grupes santykiu 2:1 vienos grupès tiriamieji ì kiekvieną nosies landą purškè po vieną ịpurš- kimą vaistinio preparato MP29-02 du kartus per parą (bendra azelastino hidrochlorido ir flutikazono propionato paros dozè buvo atitinkamai 548 ir $200 \mu \mathrm{g})$; kitos grupès - vieną kartą per parą i kiekvieną nosies landą po 2 ipurškimus flutikazono propionato (bendra paros dozè - $200 \mu \mathrm{g}$ ).

Tiriamojo vaistinio preparato MP29-02 saugumas ir toleravimas klinikinio tyrimo metu buvo vertinami praejus 1, 3, 6, 9 ir 12 mèn. nuo MP29-02 vartojimo pradžios. Vaisto saugumo duomenys buvo vertinami atsižvelgiant i nepageidaujamų reiškinių dažnumą, tipą ir sunkumą. Lengvu nepageidaujamu reiškiniu laikyta būklè, kai tiriamasis jautè tam tikrus rinito simptomus, tačiau jie nekèlè diskomforto ir buvo laikomi kliniškai nereikšmingais; vidutinio sunkumo nepageidaujamu reiškiniu - kai tiriamasis jautè diskomfortą dèl AR simptomų, buvo sutrikdyta îprastinè veikla ir laikyta, kad būklès pokyčiai turi tam tikros klinikinès reikšmės; sunkus kai tiriamasis negalèjo normaliai dirbti arba atlikti iprastų kasdienių darbų, o pakitusios būklès klinikine reikšme neabejota [17]. Su tiriamuoju vaistu susijusių nepageidaujamų reiškinių dažnumas buvo mažas tiek MP29-02 $(9,4$ proc.), tiek flutikazono propionato $(11,1$ proc.) grupèse. Neišryškejjo ir jokių vẻlyvųjų nepageidaujamų reiškinių. Atliekant nuolatinę nosies pertvaros, gleivinès apžiūra, ypač atkreipiant dèmesi i MP29-02 grupés pacientus, nepastebèta nei nosies gleivinès opèjimo, nei pertvaros perforacijos. Neregistruota ir jokių neiprastų nepageidaujamų akių reiškinių ar kliniškai svarbių laboratorinių pokyčių. Tyrimo MP29-02 metu grupelei tiriamųjų buvo tiriama kortizolio koncentracija serume nevalgius, nes, literatūros duomenimis, ilgalaikis inhaliuojamųjų GKK vartojimas gali slopinti antinksčiuc linijos hipofizès-pagumburio veiklą. Tačiau reikšmingu skirtumų, galinčių sustiprinti hipofizès-pagumburio antinksčių linijos slopinimą vartojant Dymista ${ }^{\oplus}$, lyginant su flutikazono propionatu, nepastebèta. Tyrime nustatyta, kad reikšmingų skirtumų saugumo atžvilgiu tarp abiejų tiriamųjų grupių (MP29-02 ir flutikazono propionato) nèra, o vaistinis preparatas MP29-02 yra gerai toleruojamas bei saugus vartoti sergant AR [17]. 


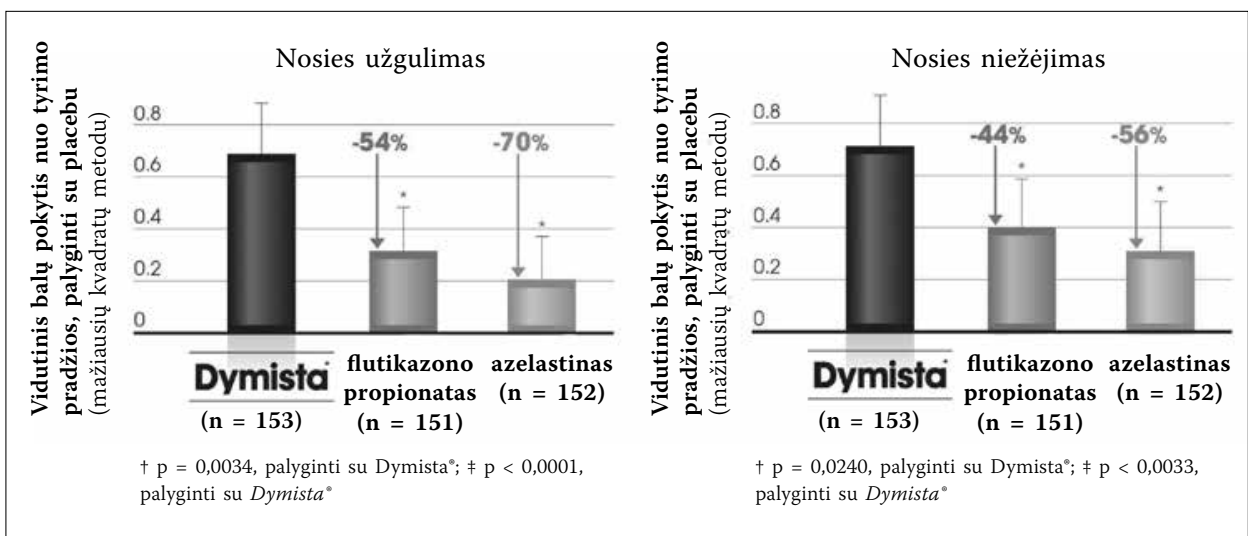

1, 2 pav. Nosies užgulimo ir niežejimo gydymo skirtingais vaistiniais preparatais veiksmingumas
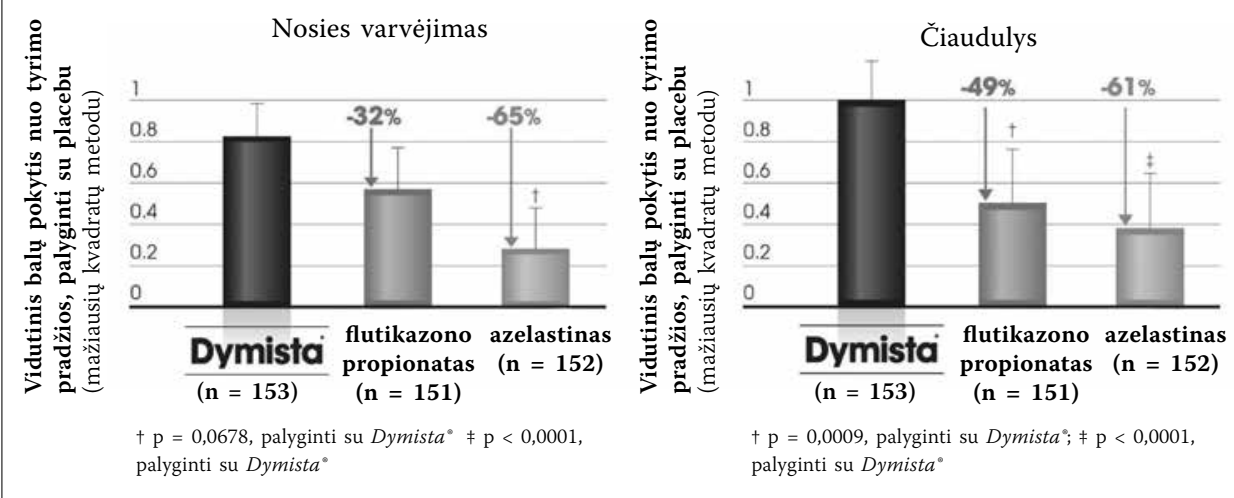

3, 4 pav. Nosies varvejjimo ir čiaudulio gydymo skirtingais vaistiniais preparatais veiksmingumas

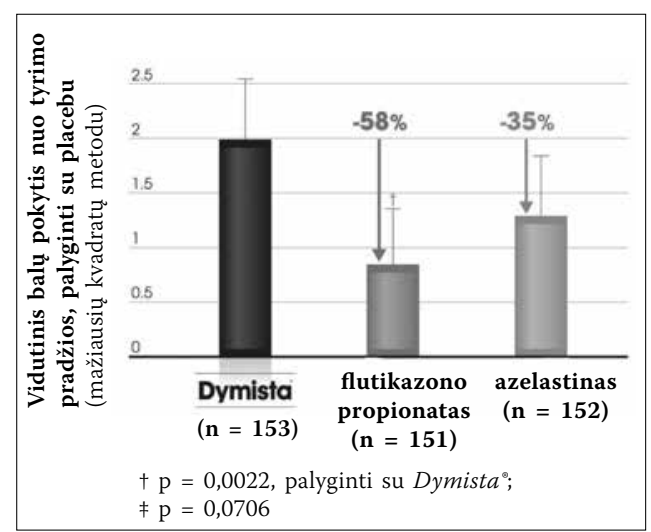

$\mathbf{5}$ pav. Alerginio konjunktyvito gydymo skirtingais vaistiniais preparatais veiksmingumas

Neretai AR sergantys pacientai siekdami greitesnio ir veiksmingesnio nosies ir akių simptomų palengvejjimo vartoja daug vaistų. MEDA klinikinès plètros programoje tiesiogiai palyginti pirmos eilès vaistai AR gydyti [3]. Atlikti keturi III fazès daugiacentriai atsitiktinių imčių placebu kontroliuojami dvigubai akli paralelinių grupių tyrimai; vienas ilgalaikis atviras saugumo tyrimas [18-21]. Iš

\section{IŠVADOS}

Alerginis rinitas - aktuali visuomenès sveikatos problema, lemianti nemenką ekonominę naštą. AR gydymo efektyvumo, o svarbiausia - ligonio gyvenimo kokybès klausimas sèkmingai sprendžiamas pasirinkus tinkamą vaistą. Dymista ${ }^{\oplus}$ efektyvumą ir saugumą patvirtina atlikti klinikiniai tyrimai. Dymista ${ }^{\circ}$ veiksmingiau už rinkoje esančius pirmos eilès vaistus palengvina nosies simptomus (rTNSS), akių simptomus (rTOSS) tiek sergantiems vidutinio sunkumo, tiek sunkios eigos AR, lyginant su atskirai vartojamu flutikazono propionatu ar azelastinu. Dymista $a^{\circ}$ papildomo efektyvumo suteikia ne tik sudètinès vaistinès medžiagos, bet ir purkštuvo technologija [22, 23].

\section{TREATMENT EFFICIENCY OF ALLERGIC RHINITIS DEPENDS ON PROPERLY CHOICE OF DRUG}

VIRGINIJA KALINAUSKAITE

DEPARTMENT OF PULMONOLOGY AND IMMUNOLOGY ACADEMY OF MEDICINE LITHUANIAN UNIVERSITY OF HEALTH SCIENCES

Keywords: moderate/severe Allergic rhinitis, Azelastine, Fluticasone.

Summary. Allergic rhinitis is a prevalent, underestimated, and undertreated condition, affecting 25 percent people in Europe [1] and about 30 percent in US [2]. Although allergic rhinitis is not life-threatening disease, but there is no doubt of its socio-economic burden. Direct medical cost per one person with allergic rhinitis is about 4260 euros per year. Allergic rhinitis worsens the quality of life as well. Therefore, a main goal of patient and physician is to reduce the symptoms of allergic rhinitis as soon as possible or completely avoid them by giving adequate the latest research-based treatment. Dymista ${ }^{\oplus}$ (Azelastine hydrochloride/Fluticasone propionate) effectively reduces the nose (rTNSS) and ocular (rTOSS) symptoms in patients with moderate and severe allergic rhinitis.

\section{LITERATŪRA} vidualiai vertinti nosies ir akiu simptomai. Dymista ${ }^{\oplus}$ vartojusiems pacientams nosies simptomai sumažèjo labiau nei vartojusiems flutikazono ar azelastino nosies purškalus (1, 2, 3, 4 pav.) [19].

Dymista $^{\odot}$ veiksmingiau už GKK nosies purškalus palengvina ir konjunktyvito simptomus (5 pav.).

Palyginus tyrimo metu gautus tiriamojo vaisto efektyvumo duomenis, pastebėta, kad Dymista ${ }^{\circ}$ veiksmingai gydo AR nepriklausomai nuo ligos sunkumo, o lyginant su azelastinu ar flutikazono propionatu, AR simptomai sumažèja 6 dienomis greičiau [1].
1. Derendorf H, Meltzer EO, Hermann R et al. Clinical Development of an Advanced Intranasal Delivery System of Azelastine hydrochloride and Fluticasone propionate. Monograph. Drugs of Today, 2014, 50(1):15-31.

2. "Kvèpuok.lt“ internetine prieiga https://www. kvepuok.It/alerginis-rinitas-ir-astma/issami-informacija-apie-alergini-rinita.aspx;

3. Bousquet J, Khaltaev N, Cruz AA. Allergic Rhinitis and its Impact on Asthma (ARIA) 2008 update (in collabora-tion with the World Organization, GA(2)LEN and Aller-Gen). Allergy. 2008; 63(Supll 86):160-8.

4. Herman H. Once-daily administration of intranasal corticosteroids for allergic rhinitis: a comparative review of efficacy, safety, patient preference, and cost. Am J Rhinol. 2007;21:70-9.

5. Verižnikovienè K. Alerginio rinito ypatumai ir gydymas. Farmacija ir laikas, 2005, 3:25-6.

Kiti literatūros šaltiniai (iš viso 23) redakcijoje. 